AperTO - Archivio Istituzionale Open Access dell'Università di Torino

\title{
Lentification in Alpine rivers: patterns of diatom assemblages and functional traits
}

\section{This is the author's manuscript}

Original Citation:

\section{Availability:}

This version is available http://hdl.handle.net/2318/1672351

since 2019-01-30T14:31:08Z

Published version:

DOI:10.1007/s00027-018-0587-y

Terms of use:

Open Access

Anyone can freely access the full text of works made available as "Open Access". Works made available under a Creative Commons license can be used according to the terms and conditions of said license. Use of all other works requires consent of the right holder (author or publisher) if not exempted from copyright protection by the applicable law. 


\section{Lentification in Alpine rivers: patterns of diatom assemblages and functional traits}

Falasco E. ${ }^{1}$, Piano E. ${ }^{1}$, Doretto A. ${ }^{1,2}$, Fenoglio S. ${ }^{2}$, Bona F. ${ }^{1}$

${ }^{1}$ DBIOS, Università degli Studi di Torino, via Accademia Albertina 13, 10123 Turin, Italy

${ }^{2}$ DISIT, Università del Piemonte Orientale, Viale Teresa Michel 25, I-15121 Alessandria, Italy.

Corresponding author: elisa.falasco@unito.it

Tel. +39347.8232078

Fax. +39011.6704508

\section{Acknowledgements}

This work is part of the research fellowship "From perennial to intermittent: structural and functional responses of benthic diatom communities in Alpine and Appenninic rivers" funded by the Italian Ministry of Research (MIUR) in the framework of the Research Project of National Interest (PRIN) "NO ACQUA”, grant number 201572HW8F. 


\begin{abstract}
Hydrological alterations in Alpine rivers have been largely increasing due to the combined effects of global climate change and local impacts. Water flow intermittency starts with a process called lentification, which leads to the transformation of the aquatic ecosystem with severe consequences on biotic communities. These consequences have a greater impact in Alpine headwater streams, which are considered important and fragile hotspots of biodiversity and a source of threatened species; the new regime creates conditions to which native biota are poorly adapted. The main aim of our work was to evaluate taxonomical, functional and structural changes of diatom communities in Alpine rivers during the lentification process that precedes a supra-seasonal drought. Contrary to what was expected, communities exposed to river shrinking showed a level of homogeneity comparable to those collected in permanent sections. We therefore hypothesized that lentification created an intermediate disturbance that favoured heterogeneity of assemblages. Conversely, ecological guilds, growth forms and eco-morphological groups varied along temporal and spatial gradients driven by the lentification process. Small, motile and medium-sized low profile species were more abundant during summer, as well as adnate and stalked ones. Lentification limited the presence of high profile guilds and mucous-forming colonies. Droughts in Alpine streams are fairly recent processes, and the dynamics of aquatic communities facing water scarcity are largely unknown. The results we obtained provide important insights towards a more refined functional classification of diatoms for evaluating hydrological alterations.
\end{abstract}

Keywords: Bacillariophyceae, hydrological alterations, ecological guilds, growth forms, eco-morphological groups 


\section{INTRODUCTION}

In some hydroecoregions, such as those in the Mediterranean, the natural hydrological cycle is characterised by flow variation. In these ecosystems, seasonal droughts shape biological communities, which in turn have evolved resistance mechanisms and resilience strategies to survive during dry periods and easily recover during rewetting (Lake 2003). In recent decades in the Alpine area, global climatic change and direct anthropogenic impacts have been exacerbating the frequency and duration of "supra-seasonal droughts" (Fenoglio et al. 2007). During the $20^{\text {th }}$ century, a general decrease in snow cover, together with an increase in the annual temperature and air pressure, have been observed in the Alps (Bard et al. 2015). At the same time, local impacts caused by water abstraction have been rapidly spreading and this stress is predicted to increase (Sabater and Tockner 2009). Over the last 150 years, a significant decreasing trend in the annual runoff for five major Italian rivers of the Central Alps has been observed (Ranzi et al. 2016).

In all river typologies, natural streamflow regimes shape the structure and function of the ecosystem, sustaining biodiversity, ecological integrity and ecosystem services (Dudgeon et al. 2006; Poff and Zimmerman 2010). Hydrological variations cause severe chain effects, ranging from the alteration of energy flux dynamics within food webs that lead to their collapse to far-reaching impacts on the functioning of the whole river ecosystem (Ledger et al. 2013). The consequences of these alterations on biotic communities are severe, as the new regime creates new conditions to which native biota may be poorly adapted. This leads to the homogenization of biological communities with consistent loss of taxa, especially the most sensitive ones, and could facilitate the successful establishment of nonnative species (Dugeon et al. 2006; Sabater and Tockner 2009; Stagl and Hattermann 2016). The consequences of water scarcity are even more important in Alpine headwater streams, which are considered fragile ecosystems and important hotspots of biodiversity, hosting rare and threatened species. In the study of Falasco et al. (2011), about 56\% of the diatom species recorded in a set of freshwater bodies of the Maritime Alps Natural Park (Gesso della Valletta and Lourousa Valleys - NW Italy) were classified as endangered at different levels (Lange-Bertalot and Steindorf 1996). Similar results were obtained in the Valasco Valley, where about $30 \%$ of the recorded species were classified as "decreasing" or "endangered" according to the German Red List (Falasco and Bona 2011).

Water temporality starts with a process called "lentification" (Sabater 2008), which leads to the transformation of the ecosystem, from lotic to lentic, with an increase in water temperature and high evaporative losses. Lentification can lead to an increase in nutrient and pollutant concentrations that, combined with higher temperature and light availability, trigger eutrophic conditions (Sabater and Tockner 2009). During this phase, shrinking of the river leads to the loss of riffle zones and the formation of pools that are initially connected to the river and then become isolated. In these pools, primary production may significantly increase due to greater light penetration and higher nutrient concentrations. Indeed, Ros et al. (2009) observed higher algal biomass in the pools of a semi-arid stream than in riffles, in association with temperature, conductivity and ammonium concentration.

The consequences of lentification and supra-seasonal droughts on biological communities have been analysed already on macroinvertebrates (Boulton and Lake 2008; Calapez et al. 2014; Smith et al. 2017). Under these conditions, benthic invertebrates displayed a general impoverishment in coenoses and the loss of sensitive taxa; i.e., shredders and scrapers that were generally replaced by small, fast-growing and plurivoltine organisms. In addition to the decrease in species richness, droughts usually cause a collapse in invertebrate abundance (Stubbington et al. 2009). 
Although diatoms are considered one of the most sensitive components of periphyton in terms of desiccation (Sabater et al. 2016; Piano et al. 2017), the effects of supra-seasonal droughts on diatoms have been poorly studied, especially from a functional point of view. To our knowledge, only Elias et al. (2015) and B-Béres e al. (2014) have explored this aspect. Elias et al. (2015) investigated biological traits of diatoms that can confer an advantage in case of unpredicted supra-seasonal drought. The authors found that the drought event led to a shift in the proportion of particular traits of communities, and some differences (such as the decrease of stalked taxa) persisted even 1 year after the disturbance. BBéres et al. (2014) analysed the changes in guild proportions within diatom communities during changing discharge. In this case, they noticed a positive correlation between water discharge and low profile diatoms, while motile taxa were mainly associated with a decrease in water discharge that was coupled with an increase in total nitrogen and total phosphorous.

The main aim of our work was to evaluate taxonomical, functional and structural changes of diatom communities in Alpine rivers during the lentification process preceding a supra-seasonal drought (also called shrinking). In particular, we assessed if the disturbance created by lentification led to a spatial and/or temporal homogenization of diatom communities by comparing permanent and intermittent sections sampled from early spring to late summer. Moreover, we explored the role of lentic microhabitats as refuges for diatoms during shrinking of the river. Finally, we analysed which were the statistically significant indicator species during the lentification process (over time and space).

Our hypotheses were: i) global heterogeneity of diatom communities is lower in sections subject to lentification (i.e. intermittent vs. permanent sites) and, at the same time, heterogeneity diminishes with the progression of lentification (i.e. from early spring to late summer); ii) microhabitats created by lentification host diatom communities that are more heterogeneous than those colonizing riffles, due to the higher microhabitat diversity; iii) there is a turnover in diatom communities due to changes induced by the lentification process. This turnover could be assessed through taxonomical changes, which are often coupled with functional changes, and examined in terms of ecological guilds, growth forms, class size and eco-morphological groups. Concerning ecological guilds and growth forms, we hypothesised that the following traits would represent an advantage during lentification: motility (motile taxa have the possibility to move towards the most suitable habitat, avoiding the disturbance and exploiting refuges), the possibility to form colonies, and small size (both of which provide protection against desiccation). Conversely, stalked cells as well as large-sized individuals, would be disadvantaged by lentification and drought as they are more exposed to desiccation. In the present work, we used a new classification in eco-morphological groups proposed by B-Béres et al. (2016). Through this approach, we aimed to test if a more refined functional classification of diatoms could be successfully used in evaluating the disturbance created by lentification.

\section{MATERIALS AND METHODS}

\section{Site selection}

An increasing number of streams in the North-Western Italian Alps are affected by supra-seasonal droughts during the summer. This study was performed in three rivers of this area, the Po, Pellice and Varaita Rivers (Fig. 1). For each, we selected two sites: the first characterized by permanent flow throughout the entire year (i.e. upstream, UP) and the second site was subject to seasonal droughts during the hot months (i.e. downstream, DW). In the following section, we 
provide a brief description of the sampling sites in terms of location and surrounding land use, which was calculated within a $1 \mathrm{~km}$ buffer around each sampling site based on the land use cartography provided on the Regione Piemonte web site (http://www.geoportale.piemonte.it/cms/). The UP site of the Po river is located about $23 \mathrm{~km}$ from the source, at $471 \mathrm{~m}$ a.s.l.; the main land-use surrounding the stretch is represented by arable lands (about 31\%) and forests (about $31 \%$; i.e. chestnuts and locust trees), while about $20 \%$ is covered by pasture. The Po river DW site is located about 7 $\mathrm{km}$ away from the upstream station, at $393 \mathrm{~m}$ a.s.l.; the main land use of this site is represented by agricultural areas (about 70\%; i.e. croplands, orchards and vineyards). About $68 \%$ of the buffer around the UP section of the Pellice River (410 $\mathrm{m}$ a.s.l. and about $30 \mathrm{~km}$ from the source) is represented by orchards and vineyards, along with the corresponding DW section (about $58 \%$ of the area included in the buffer). The intermittent site on the Pellice River is located about 3 $\mathrm{km}$ downstream of the permanent section and, apart from the agricultural land use, the riparian forest covers about $26 \%$ of the buffer surface. The UP section of the Varaita river is located just upstream of Costigliole Saluzzo (CN), a small village with about 3000 inhabitants located about $50 \mathrm{~km}$ from the Varaita spring, at $448 \mathrm{~m}$ a.s.l. Apart from this small urban area, about $40 \%$ of the surrounding land is dedicated to croplands, orchards and vineyards, while $10 \%$ is represented by riparian forest. The DW station of Varaita is located $4 \mathrm{~km}$ away from the UP site, at $400 \mathrm{~m}$ a.s.l., and its main land use is represented by agricultural areas (about 63\% of the buffer) and by the riparian zone (about $16 \%$ ). During 2017, we performed monthly sampling sessions, from early spring (March) to late summer (August), following the lentification process preceding the complete drying of the riverbed. According to the standard procedure (European Committee for Standardization 2003), at each site we selected a segment of river characterized by riffles and substrata suitable for sampling (hereafter "transect" -T-) and two microhabitats (MH) differing from the transect in terms of water velocity, depth, macrophyte coverage, substrate composition and shade. When present, isolated pools were preferentially selected as $\mathrm{MH}$, and were considered as possible refuges for the diatom community.

\section{Physical and chemical parameters}

On each sampling occasion, we measured major physical and chemical parameters. In particular, temperature, dissolved oxygen, $\mathrm{pH}$ and conductivity were measured by means of a multiparametric probe (Hydrolab mod. Quanta). Current velocity was measured by means of a current meter (Mod RHCM Idromar) placed at $0.05 \mathrm{~m}$ from the bottom of the riverbed. Water depth was measured by means of a meter tape. Flow velocity and depth were detected in both $\mathrm{T}$ (average values of three measures collected along the transect) and MHs. Water samples were collected for soluble reactive phosphorous (SRP) and nitrate (N-NO3) analyses, which were performed in the laboratory by means of a LASA100 spectrophotometer according to APAT-IRSA CNR standard methods (APAT IRSA 2003).

\section{Diatom analyses}

At each sampling site, we collected three epilithic diatom samples (1 $\mathrm{T}$ and $2 \mathrm{MHs}$ ). Diatoms from $\mathrm{T}$ were collected by means of a toothbrush, by scraping the surface of three cobbles positioned along a transect. The diatom samples from MH were collected by scraping the surface of one single cobble in order to reduce the effect of substrate typology and focus on the effect of the surrounding environment. Diatom samples were preserved in ethanol. In the laboratory, samples were treated following the standard procedure (European Committee for Standardization 2003) by cleaning 
them with hydrogen peroxide (30\%) and $\mathrm{HCl}(1 \mathrm{~N})$. Slides for light microscope analysis were mounted in Naphrax ${ }^{\circledR}$ resin.

Diatom identification was performed according to the most common European diatom floras and monographies as well as recent taxonomic papers (see Falasco et al. 2016 for further details). For each slide, we identified at least 400 valves.

Finally, each taxon was assigned to the following groups: i) ecological guilds (low profile, high profile, motile and planktic; according to Rimet and Bouchez 2012); ii) growth forms (adnate, mucous-forming, stalked, pad-attached, colonial; according to Rimet and Bouchez 2012); iii) class size (size 1=0-99 $\mu \mathrm{m}^{3}$, size 2: 100-299 $\mu \mathrm{m}^{3}$, size 3: 300-599 $\mu \mathrm{m}^{3}$, size 4: 600-1499 $\mu \mathrm{m}^{3}$, size 5: over $1500 \mu \mathrm{m}^{3}$; according to Rimet and Bouchez 2012); iv) eco-morphology (referring to B-Béres et al. 2016). According to this last classification, each of the four ecological guilds, could be further divided into five size classes (see above). The combination of these $4^{\mathrm{x}} 5$ ecological traits results in 20 ecomorphological groups.

\section{Statistical analyses}

All statistical analyses were performed in the R environment (R Core Team 2017).

To test the effects of river shrinkage on diatom communities, we identified four factors to be used as explanatory variables i) "month", i.e. the temporal sampling session (March, April, May, June, July and August), which considers the temporal trend in river shrinkage; ii) "site", i.e. UP and DW sites, which represents the spatial trend in river shrinkage; iii) "sample", i.e. $\mathrm{T}$ and MH samples, which describes the fragmentation process; iv) "velocity", i.e. lentic and lotic microhabitats (flow velocity $=0 \mathrm{~m} / \mathrm{s}$ or flow velocity $>0 \mathrm{~m} / \mathrm{s}$ ), as proxy for the lentification process.

To test whether river shrinkage causes homogenization of benthic diatoms, we performed a test of homogeneity multivariance dispersion (Anderson et al. 2006). For this purpose, we constructed a site-by-species matrix (hereafter called taxonomic matrix), with the relative abundance of each recorded taxon in each sample. The taxonomic matrix was then converted into a site-by-site distance matrix using the Bray-Curtis distance with the function "vegdist" in the package vegan (Oksanen et al. 2017), to which we applied the test of homogeneity multivariate dispersion performed with the function "betadisper". With this test, we aimed to test differences in diatom community composition between the levels of our four explicative factors. We therefore repeated the test for each factor and, for each of the four tests, the distance of each site from its associated group median was calculated. Site distances from median values were subjected to ANOVA with 9999 permutations to determine whether the dispersion of one or more groups differed and the Tukey's post-hoc test was used for pairwise comparisons.

To detect which factors cause shifts in diatom community composition, we applied a PERMANOVA test (Anderson 2001) to the distance matrix including the four factors in the analysis.

To analyse the response of functional traits to river shrinkage, we created a site-by-trait matrix (hereafter called functional matrix) containing trait abundances for each site. To generate the functional matrix, we first created a species-by-trait matrix that was multiplied by the species-by-site matrix to obtain the site-by-trait matrix with the function "functcomp" in the package $F D$ (Laliberté et al. 2014), in which each entry corresponded to the sum of the relative abundances of all the species with a particular trait present in a site. We tested the effects of our explanatory 
factors by means of a multi-way ANOVA test, with the river identity as the random factor. Differences between levels of our factors were tested with a Tukey's post-hoc test.

To check whether specific species are indicators of one particular level of our factorial variables we performed the Indicator Species Analysis (Dufrêne and Legendre 1997) with the function "multipatt" in the package indicspecies (Caceres and Legendre 2009).

\section{RESULTS}

\section{Physical and chemical parameters}

The permanence of surface water varied in the three rivers considered. In the Pellice River, water flow persisted from March to August, when the DW section was almost dry, with just two residual and isolated pools. In the Po and Varaita, the DW sites dried during July and June, respectively. While the Po River fragmented into several isolated habitats, the drought was so rapid and sudden in the Varaita that no pools had time to form.

Physical and chemical parameters detected throughout the entire survey are displayed in Table 1. Conductivity and pH were in the same order of magnitude in all three rivers, with slightly higher values in the Varaita than in the Po or Pellice. We found that the water quality was good in all the three rivers, in both sections and during the entire experiment. Nitrate was slightly higher in the Po River with peaks in March and July in some isolated microhabitats of the DW. Despite this, we can state that $\mathrm{N}_{-} \mathrm{NO}_{3}$, on average, was in the second quality class proposed by the Italian Water Legislation, and SRP was always very low, corresponding to oligo or $\beta$-mesotrophic status (D. Leg. 152/2006 and successive ones). Water temperature increased from March to August with a peak in the DW section of the Varaita $\left(\mathrm{T}=22.8^{\circ} \mathrm{C}\right)$.

\section{Diatom community composition}

In total, we analysed 89 samples and identified 162 taxa (see Electronic Supplementary Material 1 for further details). In the Pellice River, the diatom community was composed of commonly widespread $\beta$-mesosaprobic species. We observed a decrease in the Shannon diversity index during May and June, compared to early spring and late summer (Electronic Supplementary Material 2), while species richness was lower in the DW section than in the UP sites. The most frequent and abundant taxa were Achnanthidium pyrenaicum and Achnanthidium minutissimum, which dominated the community throughout the study, both in UP and DW sections, together representing more than $50 \%$ of the community. See Supplementary Material 2 for details on the list of the species recorded during the experiment. Cocconeis lineata and Encyonema silesiacum were also very abundant, but with opposite trends, the former being more abundant during May and June, the latter during spring. Encyonema minutum presented a similar pattern as E. silesiacum, as its abundance gradually decreased from March to June. Conversely, Nitzschia fonticola, N. archibaldii and Ulnaria ulna were more abundant during the summer months.

In the Po River, A. pyrenaicum and A. minutissimum were also very abundant in all the samples, reaching lowest values in the DW during May. Conversely, they represented more than $70 \%$ of the community during July. As in the Pellice River, C. lineata and E. silesiacum showed an opposite seasonal trend and E. minutum decreased through the summer 
but never disappeared. During late spring and in summer, the Po DW site was characterized by the presence of Achnanthidium gracillimum, which showed peaks of abundance in an isolated microhabitat (about 47\% during May and about 53\% during June). No data coming from the same microhabitat were available for July and August due to complete drying of the pool.

In the Varaita River, A. pyrenaicum and A. minutissimum were the dominant taxa. Unlike the other rivers, the abundance of $C$. lineata was negligible during the entire survey, and E. silesiacum was constantly present and abundant even during summer. The analysis of the community composition also revealed a significant presence of Diatoma ehrenbergii, especially during spring.

With the exception of the Po UP site, we detected the presence of the invasive diatom species Didymosphenia geminata throughout the entire study, in all rivers, in both UP and DW sites. However, previous surveys also confirmed the presence of this species in the upper sections of the Po, even close to its springs (personal observation).

\section{Heterogeneity of diatom communities across spatial and temporal gradients}

The test of homogeneity for multivariate dispersion highlighted that there was no homogenization of communities across the temporal gradient, or between UP and DW sites (Table 2). In other words, we observed no simplification of communities with drought progression (comparison between months) nor between permanent and intermittent sections (comparison between UP and DW). Conversely, there was a significant difference in heterogeneity at the local scale, with microhabitat samples more heterogeneous, on average, than those collected in the transects (Table 2). If we consider flow velocity, we observed that standing waters had more heterogeneous communities than lotic sections; indeed, it seems that communities colonizing flowing habitats were a subset of the lentic ones, as the river flow probably only selected species adapted to riffles, even when flow was only perceivable.

\section{Turnover of species and functional groups}

Although we observed no homogenization of communities during the lentification process, the PERMANOVA test highlighted a species shift due to all measured factors, apart from flow velocity (Table 3).

There was a gradual change in diatom community composition with drought progression (i.e. from early spring to late summer, when the disturbance reached its maximum). In general, we observed a gradual increase in low profile guilds and a steep augmentation of motile taxa, especially during July and August.

Conversely, the percentage of high profile guilds generally decreased and the results of the multi-way ANOVA test confirmed this trend (Table 4). Motile taxa were significantly affected by sampling month, being more abundant in July than previous months (Tukey's post-hoc test: $\mathrm{p}$ <0.007). High profile taxa showed an opposite trend, diminishing with drought progression; in particular they were significantly more abundant in March and April than subsequent months (Tukey’s post-hoc test: $\mathrm{p}<0.037$ ). Moreover, high profile guilds were represented to a greater extent in MH than T (Tukey's post-hoc test: $\mathrm{p}=0.020$ ). The trend in the low profile guilds was less clear, however we detected significant differences between sampling months with lower values in March and April and higher abundances in June and August (Tukey's post-hoc test: $\mathrm{p}<0.041$ ). Furthermore, the low profile guilds were significantly more abundant in $\mathrm{T}$ than in MH ( $\mathrm{p}=0.030)$. Planktonic species were significantly more abundant in intermittent sections (Tukey's post-hoc test: $\mathrm{p}=0.038$ ). However, the low representation of this guild (high zero inflation) in our samples reduced the statistical power of the analysis. 
Concerning life forms, we observed that adnate taxa were more abundant in June than March (Tukey's post-hoc test: $\mathrm{p}$ =0.007). Colonial "mucous forming" taxa were significantly affected by sampling month and site, being more abundant in spring than summer (Tukey's post-hoc test: $\mathrm{p}=0.027$ ) and in microhabitats than transects (Tukey's post-hoc test: $\mathrm{p}$ $=0.024)$. Stalked forms were more abundant in June compared to March (Tukey’s post-hoc test: $p=0.007$ ), while padattached forms had an opposite trend with higher values in March compared to June (Tukey's post-hoc test: $p=0.044$ ). Colonial forms decreased with the lentification progression, being more abundant in March and April than late spring or summer (Tukey's post-hoc test: $\mathrm{p}<0.045$ ). In general, they were related to more lentic flows, even if this was not statistically significant (Tukey's post-hoc test: $\mathrm{p}=0.053$ ).

We did not observe any significant differences in diatom class size according to sampling month, site or habitat.

The eco-morphological groups generally confirmed the previous results concerning month preferences and provided new insights on site location, habitat features and flow velocity. In particular, some groups were significantly characteristic of downstream sections (i.e. LS3 and MS1; Tukey's post-hoc test: $p=0.013 ; \mathrm{p}=0.04$, respectively), while LS2 was typical of permanent sites (Tukey's post-hoc test: $p=0.039$ ). Concerning habitat preferences, the small low profile group (LS2) showed higher abundances in T than in MH (Tukey's post-hoc test: $\mathrm{p}=0.002$ ), unlike HS2 and HS4 which were typical of MHs (i.e. HS2 and HS4; Tukey's post-hoc test: $p=0.011 ; p=0.021$, respectively). In general, large-sized taxa within low profile and motile guilds preferred standing waters (i.e. LS3 and MSS4; Tukey's post-hoc test: $\mathrm{p}=0.024 ; \mathrm{p}=0.038$, respectively).

The statistically significant occurrence of species in terms of sampling month and site or habitat are shown in ESM1 (column ISA).

\section{DISCUSSION}

Contrary to what was expected, we did not observe a homogenization of the communities exposed to river shrinkage. Our results highlighted that the differences in species composition between diatom communities were mainly driven by habitat features, and the test of homogeneity for multivariate dispersion detected a significant difference between $\mathrm{MH}$ and T. Regarding water quality, we did not detect a clear trend in nutrient concentration or physical-chemical parameters. Indeed, the phosphorous concentration always corresponded to a trophic level ranging from oligo- to $\beta$ mesotrophic, on average never exceeding $19 \mu \mathrm{g} / \mathrm{l} \mathrm{SRP}$. Concerning conductivity, we did not detect any clear differences throughout the study period in the three rivers. Conductivity levels were slightly higher in the Varaita than in the Po and Pellice according to their respective geological substrate. In general, we do not believe that these slight differences could have driven the differences in diatom communities. Community heterogeneity was comparable in upstream and downstream sites, and from March to August. Diatom communities of transect sections were a subset of communities collected in microhabitats. During late spring and summer, microhabitats were mainly represented by lentic sections and isolated pools, which are typical habitats generated by lentification.

In this study lentic habitats sheltered species presenting unsuitable traits to resist to high-flow velocities, but adapted to live in the epipelon and able to move within the sediment deposit (i.e. species belonging to the genera Navicula and Nitzschia). Our results were in accordance with those highlighted by Ros et al. (2009), who detected higher abundances of some motile taxa in association with pools compared to fast-flowing sections. Motile taxa have a competitive 
advantage compared to sessile diatoms, since they can actively move towards more suitable conditions (Svensson et al. 2014 and references therein) and avoid disturbed sections, such as those created by lentification, thus colonizing refuges. Moreover, it seems that an increase in water temperature decreases the viscosity of cytoplasm in the raphe slit, enhancing the ability of motile taxa to move (Hope and Walker 1975). Motile taxa were more abundant during the hot months and in downstream microhabitats, while low profile species were significantly more abundant in the transects, confirming their tolerance to scouring and high-flow velocity (Tang et al. 2013).

We found that colonial species showed a decrease in abundance from spring to late summer. However, it should be considered that some of the species classified as colonial, such as Fragilaria arcus or Meridion circulare, are also considered reophilous taxa as they are adapted to live under high-flow conditions (Denys et al. 1991).

The fact that mucous-forming taxa were more abundant in spring than in summer is in contrast with our initial hypothesis. The shelter offered by the extracellular polymeric substances produced by these taxa, should protect the cells from desiccation, therefore representing a mechanism to resist drought (Elias et al. 2014). This result was probably due to the fact that we never sampled completely dried sites, since we monitored the lentification process, not completely dry riverbeds. The pattern followed by mucous-forming taxa, such as those belonging to the genus Encyonema, also seems related to the presence of Didymosphenia geminata, confirming previous results (Spaulding et al. 2010; Ladrera et al. 2018).

We did not detect any significant differences between sampling months, sites or habitats concerning diatom class size. Even though it has been already demonstrated that an increase in water temperature can shift phytoplankton size towards smaller individuals (Svensson et al. 2014 and references therein). Our results are in accordance with Adams et al. (2013), who showed that diatoms represent an exception to the temperature-size rules at both the species and community levels.

New insights were provided by classification into eco-morphological groups recently proposed by B-Béres et al. (2016). These authors hypothesised that taxa belonging to the same guild, but possessing different body size, can behave in different ways during the colonization process. Indeed, they found that the new groups provided more robust responses to environmental parameters than a sole analysis with guilds or class size. In our study, this new classification shed light on contrasting results obtained through the analysis of ecological guilds. For instance, the trend followed by the low profile guilds was not very clear; this was probably due to the fact that while almost all the class sizes were more abundant during spring than in summer, the LS2 class followed an opposite pattern. The species which mainly drove this trend were Achnanthidium minutissimum and A. pyrenaicum, belonging to LS1 and LS2, respectively, and representing the most abundant taxa during the entire experiment. Another important insight was the role of small motile taxa as indicators of downstream sections. The most abundant species belonging to this category were Mayamaea permitis, Adlafia minuscula, Nitzschia inconspicua and Sellaphora nigri.

The Indicator Species Analysis (ISA) gave us the opportunity to highlight the presence of statistically significant indicator species, reinforcing the knowledge on their ecological preferences towards a better definition of their ecological niches. The results of the ISA were in accordance with those detected by B-Béres e al. (2014), who found that Fragilaria species sensu lato and Nitzschia species were mainly associated with standing water segments. In the present study, we recorded a species belonging to the genus Fragilaria (in our study called Fragilaria sp.), which does not show taxonomic correspondence to any other described species, and which may represent a new species. We personally observed that this same species was also abundant in the Mediterranean hydroecoregion, and can reach high 
relative abundances in the intermittent typology. Considering this, we think that further taxonomic studies on this taxon are necessary. The development of the genus Fragilaria has been recognized to be favoured by short-term fluctuations in the water level (see Sánchez-Castillo et al. 2008 and references therein) and our results seem to confirm this observation. This was not the first time we detected more abundant presence of A. gracillimum in MH rather than T, mainly associated with lentic habitats (Falasco et al. 2016). A. gracillimum is considered a sensitive species, typical of oligothrophic waters and classified as "endangered" according to the German Red List (Lange-Bertalot and Steindorf 1996). Its ability to survive and reproduce in rivers affected by hydrological disturbance should be considered an important advantage.

Our results are consistent with those obtained by García et al. (2008), who observed that the succession within diatom communities are mainly driven by flow, but from our results, lentification is not a limiting factor for diatom development, at least in the first steps of the process. While on one hand, lentification could be considered a stress for the aquatic biota, on the other hand it creates very heterogeneous patches with lotic, lentic and terrestrial compartments, which can be colonised by a large number of species, characterized by wide ecological preferences. In this phase, the river is characterized by greater habitat heterogeneity than during undisturbed conditions in terms of flow typologies, water level, sediment transport and deposition, temperature, PAR and so on. Under these conditions, $\beta$-diversity can be higher than expected (Tang et al. 2013; Sabater et al. 2016), since it seems that biological communities are able to better exploit water resources in spatially heterogeneous channels or under intermediate disturbance than during stable conditions (Sabater 2008).

Lepori and Hjerdt (2006) examined two contrasting theories dealing with the role of disturbance on the biodiversity of aquatic communities. The first focused on the role of the disturbance as an environmental filter that prevents the colonization of species that lack traits, and which confer resistance and resilience. The second theory involved the intermediate disturbance hypothesis (Connell 1978), the dynamic equilibrium model (Hudson 1979) and the patch dynamic framework (Pickett and White 1985). The lentification process creates an intermediate disturbance, which can favour assemblage richness, limiting the growth of good competitors and supporting the presence of new colonizers. However, without a doubt, the effects of droughts on primary producers can be dramatic, especially in Alpine streams where these phenomena are recent processes, and the dynamics of aquatic communities facing water scarcity are largely unknown.

The results we obtained with the new classification in eco-morphological groups can be considered as a new starting point towards a more refined functional classification of diatoms, which could be used in evaluating physical disturbance. In view of the large increase in annual water abstraction for human needs, the sustainable management of water resources must be considered as an absolute priority (Stagl and Hattermann 2016). Environmental research must carry out investigations to deepen the knowledge on the consequences of water stress on biological communities to provide support to management policies (Poff and Zimmerman 2010). From this point of view, the maintenance of a flow that mimics natural conditions, with all its variation, is fundamental to preserve aquatic biodiversity and ecosystem services, which are often irreplaceable (Dugeon et al. 2006).

\section{BIBLIOGRAPHY}


Adams GL, Pichler DE, Cox EJ, O'Gorman EJ, Seeney A, Woodward G, Reuman DC. (2013) Diatoms can be an important exception to temperature-size rules at species and community levels of organization. Glob Chang Biol. 19(11): 3540-3552

Anderson MJ (2001) A new method for non- parametric multivariate analysis of variance. Austral Ecol. 26(1): 32-46.

Anderson MJ, Ellingsen KE, McArdle BH (2006) Multivariate dispersion as a measure of beta diversity. Ecol. Lett. 9(6): 683-693

APAT-IRSA CNR (2003) Metodi analitici per le acque, vol I. Rapporti 29/2003. APAT: Roma

Bard A, Renard B, Lang M, Giuntoli I, Korck J, Koboltschnig G, Janža M, d'Amico M, Volken D (2015) Trends in the hydrologic regime of Alpine rivers. J. Hydrol. 529: 1823-1837

B-Béres V, Lukács Á, Török P, Kókai Z, Novák Z, T-Krasznai E, Tóthmérész B, Bácsi I (2016) Combined ecomorphological functional groups are reliable indicators of colonisation processes of benthic diatom assemblages in a lowland stream. Ecol. Indic. 64 (1): 31-38

B-Béres V, Török P, Kókai Z, Krasznai ET, Tóthmérész B, Bácsi I (2014) Ecological diatom guilds are useful but not sensitive enough as indicators of extremely changing water regimes. Hydrobiol. 738(1): 191-204

Boulton AJ, Lake PS (2008) Effects of drought on stream insects and its ecological consequences. Aquatic insects: challenges to populations. Wallingford, UK: CABI Publishing, 81-102

Cáceres MD, Legendre P (2009) Associations between species and groups of sites: indices and statistical inference. Ecology 90(12): 3566-3574

Calapez AR, Elias CL, Almeida SF, Feio MJ (2014) Extreme drought effects and recovery patterns in the benthic communities of temperate streams. Limnetica 33(2): 281-296

Connell JH (1978) Diversity in tropical rainforest and coral reefs. Science 199: 1302-1310

Denys L (1991) A check-list of the diatoms in the Holocene deposits of the western Belgian coastal plain with a survey of their apparent ecological requirements, vol. I. Professional Paper. Geological Survey of Belgium, 1991/02 (246). Geologische Dienst van België: Brussels, 41 pp.

Dudgeon D, Arthington AH, Gessner MO, Kawabata Z, Knowler DJ, Lévêque C, Naiman RJ, Prieur-Richard AH, Soto D, Stiassny MLJ, Sullivan CA (2006) Freshwater biodiversity: importance, threats, status and conservation challenges. Biol Rev 81:163-182

Dufrêne M, Legendre P (1997) Species assemblages and indicator species: the need for a flexible asymmetrical approach. Ecol. Monogr. 67(3): 345-366

Elias CL, Calapez AR, Almeida SFP, Feio MJ (2015) From perennial to temporary streams: an extreme drought as a driving force of freshwater communities' traits. Mar Freshwater Res 66: 469-480

European Committee for Standardization (2003) Water Quality Guidance Standard for the Routine Sampling and Pretreatment of Benthic Diatoms from Rivers. European Standard EN 13946. European Committee for Standardization: Brussels, 14 pp

Falasco E, Bona F (2011) Diatom community biodiversity in an Alpine protected area: a study in the Maritime Alps Natural Park. J. Limnol. 70 (2): 157-167

Falasco E, Ector L, Ciaccio E, Hoffmann L, Bona F (2011) Alpine freshwater ecosystems in a protected area: a source of diatom diversity. Hydrobiologia 695: 233-251

Falasco E, Piano E, Bona F (2016) Diatom flora in Mediterranean streams: flow intermittency threatens endangered species. Biodiversity Conserv. 25: 2965-2986 
Fenoglio S, Bo T, Cucco M, Malacarne G (2007) Response of benthic invertebrate assemblages to varying drought conditions in the Po river (NW Italy). Ital. J. Zool. 74(2): 191-201

García L, Delgado C, Pardo I (2008) Seasonal changes of benthic communities in a temporary stream of Ibiza (Balearic Islands). Limnetica 27: 259-272

Hope AB, Walker NA (1975) The physiology of giant algal cells, 166-167. University Press, Cambridge. Cited in: Raven JA, Geider RJ (1988) Temperature and algal growth. The New Phytologist 110: 441-461

Hudston MA (1979) A general hypothesis of species diversity. Am. Nat. 113: 81-99

Ladrera R, Gomà J, Prat N (2018) Effects of Didymosphenia geminata massive growth on stream communities: Smaller organisms and simplified food web structure. PLoS ONE $13(3)$ : e0193545. https://doi.org/10.1371/journal.pone.0193545

Lake PS (2003) Ecological effects of perturbation by drought in flowing waters. Freshw Biol 48:1161-1172

Laliberté E, Legendre P, Shipley B (2014) FD: measuring functional diversity from multiple traits, and other tools for functional ecology. R package version 1.0-12

Lange-Bertalot H, Steindorf A (1996) Rote Liste der limnischen Kieselalgen (Bacillariophyceae) Deutschlands. Schriftenreihe für Vegetationskunde 28: 633-677

Ledger ME, Brown LE, Edwards F, Milner AM, Woodward G (2013) Droughts alter the structure and functioning of complex food webs. Nat. Clim. Change 3(3): 223-227

Lepori F, Hjerdt N (2006) Disturbance and aquatic biodiversity: reconciling contrasting views. BioScience 56: 809-818 Oksanen J, Blanchet FG, Friendly M, Kindt R, Legendre P, McGlinn D, Minchin PR, O'Hara RB, Simpson GL, Solymos P, Stevens MHH, Szoecs E and Wagner H (2017). Vegan: Community Ecology Package. R package version 2.4-2

Piano E, Falasco E, Bona F (2017) Mediterranean rivers: consequences of water scarcity on benthic algal chlorophyll a content. J. Limnol. 76(s1): 39-48

Pickett STA, White PS (1958) The ecology of natural disturbance and patch dynamics. New York: Academic press.

Poff NL, Zimmerman JKH (2010) Ecological responses to altered flow regimes: a literature review to inform the science and management of environmental flows. Freshwater Biol. 55: 194-205

R Core Team (2017) R: A language and environment for statistical computing. R Foundation for Statistical Computing, Vienna, Austria. URL https://www.R-project.org/

Ranzi R, Caronna P, Tomirotti M (2017) Impact of Climatic and Land Use Changes on River Flows in the Southern Alps. In: Kolokytha E., Oishi S., Teegavarapu R. (eds) Sustainable Water Resources Planning and Management Under Climate Change. Springer, Singapore

Rimet F, Bouchez A (2012) Life-forms, cell-sizes and ecological guilds of diatoms in European rivers. Knowl Manag Aquat Ec 406: 01-12

Ros MD, Marín-Murcia JP, Aboal M (2009) Biodiversity of diatom assemblages in a Mediterranean semiarid stream: implications for conservation. Mar Freshwater Res 60:14-24

Sabater S (2008) Alterations of the global water cycle and their effects on river structure, function and services. Freshw Rev 1:75-88

Sabater S, Timoner X, Borrego C, Acuña V (2016). Stream biofilm responses to flow intermittency: from cells to ecosystems. Front. Environ. Sci. 4:14. 
Sabater S, Tockner K (2009) Effects of Hydrologic Alterations on the Ecological Quality of River Ecosystems. In: Sabater S., Barceló D. (eds) Water Scarcity in the Mediterranean. The Handbook of Environmental Chemistry, vol 8. Springer, Berlin, Heidelberg

Sánchez-Castillo PM, Linares-Cuesta JE, Fernández-Moreno D (2008) Changes in epilithic diatom assemblages in a Mediterranean high mountain lake (Laguna de La Caldera, Sierra -Nevada, Spain) after a period of drought. J. Limnol. 67(1): 49-55

Smith CR, McCormick PV, Covich AP, Golladay SW (2017) Comparison of macroinvertebrate assemblages across a gradient of flow permanence in an agricultural watershed. River Res. Appl. 33(9): 1428-1438

Spaulding SA, Pool JR, Castro SI, Hinz F (2010) Species within the genus Encyonema Kützing, including two new species Encyonema reimeri sp. nov. and E. nicafei sp. nov. and E. stoermeri nom. nov., stat. nov. Proc. Acad. Nat. Sci. Philadelphia 160: 57-71

Stagl JC, Hattermann FF (2016) Impacts of Climate Change on Riverine Ecosystems: Alterations of Ecologically Relevant Flow Dynamics in the Danube River and Its Major Tributaries. Water 8(12), 566

Stubbington R, Wood PJ, Boulton AJ (2009) Low flow controls on benthic and hyporheic macroinvertebrate assemblages during supra- seasonal drought. Hydrol. Process. 23(15): 2252-2263

Svesson F, Norberg J, Snoeijs P (2014) Diatom cell size, coloniality and motility: trade-offs between temperature, salinity and nutrient supply with climate change. Plos one 9(10): e109993

Tang T, Qian Niu S, Dudgeon D (2013) Responses of epibenthic algal assemblages to water abstraction in Hong Kong streams. Hydrobiologia 703: 225-237

\section{Figure Legends}

Fig. 1. Sampling site locations in the Pellice, Po and Varaita rivers (NW-Italy).

Table 1. Physical and chemical parameters measured in the three rivers throughout the study. Values represent the mean of the measurements detected in the UP and DW sections, in both T and MH (mean \pm standard deviation).

\begin{tabular}{|c|c|c|c|c|c|c|}
\hline \multicolumn{7}{|c|}{ Pellice } \\
\hline & March & April & May & June & July & August \\
\hline $\begin{array}{l}\text { COND } \\
(\mu \mathrm{S} / \mathrm{cm})\end{array}$ & $126 \pm 8$ & $117 \pm 0.7$ & $117 \pm 4$ & $156 \pm 20$ & $180 \pm 9$ & $196 \pm 12$ \\
\hline DO (\%) & $102.3 \pm 14.57$ & $94.0 \pm 10.0$ & $96.2 \pm 6.29$ & $95.5 \pm 5.22$ & $87.7 \pm 18.29$ & n.d. \\
\hline DO (mgl/l) & $11.4 \pm 2.40$ & $11.4 \pm 1.1$ & $10.5 \pm 0.83$ & $9.3 \pm 0.43$ & $7.9 \pm 1.66$ & n.d. \\
\hline $\mathrm{pH}$ & $7.04 \pm 0.05$ & $7.84 \pm 0.21$ & $7.46 \pm 0.10$ & $7.78 \pm 0.33$ & $8.18 \pm 0.54$ & $7.87 \pm 0.55$ \\
\hline temp $\left({ }^{\circ} \mathrm{C}\right)$ & $8.9 \pm 0.13$ & $7.2 \pm 0.59$ & $11.7 \pm 0.59$ & $16.9 \pm 0.68$ & $19.6 \pm 0.52$ & $18.2 \pm 3.20$ \\
\hline $\mathrm{SRP}(\mu \mathrm{g} \mathrm{P} / 1)$ & $15 \pm 6.4$ & $16.7 \pm 8.14$ & $0 \pm 0$ & $1 \pm 1.2$ & $10 \pm 5.2$ & $14 \pm 16$ \\
\hline NO3 ( $\mu \mathrm{g} \mathrm{N} / \mathrm{l})$ & $988 \pm 18$ & $888 \pm 126$ & $526 \pm 366$ & $747 \pm 89$ & $799 \pm 301$ & $732 \pm 307$ \\
\hline $\mathrm{NH} 3(\mu \mathrm{g} \mathrm{N1} / 1)$ & $138 \pm 30$ & $18.7 \pm 2.41$ & $14 \pm 4.2$ & $26 \pm 1.7$ & $34 \pm 1.9$ & $54 \pm 3.5$ \\
\hline \multicolumn{7}{|c|}{ Po } \\
\hline & March & April & May & June & July & August \\
\hline COND & $152 \pm 15$ & $112 \pm 8$ & $110 \pm 9$ & $\begin{array}{l}135 \pm 8 \\
14\end{array}$ & $166 \pm 6$ & - \\
\hline
\end{tabular}




\begin{tabular}{|c|c|c|c|c|c|c|}
\hline \multicolumn{7}{|l|}{$(\mu \mathrm{S} / \mathrm{cm})$} \\
\hline DO (\%) & $84.4 \pm 15.97$ & $90.5 \pm 13.42$ & $90.2 \pm 16.51$ & $98.0 \pm 9.58$ & $86.6 \pm 14.57$ & - \\
\hline DO (mgl/l) & $8.5 \pm 1.08$ & $9.9 \pm 1.28$ & $9.2 \pm 1.43$ & $10.1 \pm 1.48$ & $8.0 \pm 1.22$ & - \\
\hline $\mathrm{pH}$ & $7.60 \pm 0.64$ & $7.35 \pm 0.46$ & $7.09 \pm 0.49$ & $7.53 \pm 0.11$ & $7.33 \pm 0.65$ & - \\
\hline temp $\left({ }^{\circ} \mathrm{C}\right)$ & $12.7 \pm 5.33$ & $10.52 \pm 1.17$ & $14.2 \pm 1.52$ & $17.8 \pm 0.37$ & $18.5 \pm 1.08$ & - \\
\hline $\operatorname{SRP}(\mu \mathrm{g} \mathrm{P} / 1)$ & $13.4 \pm 11.8$ & $9.04 \pm 9.25$ & $19 \pm 10$ & $0.3 \pm 0.6$ & $10 \pm 0.5$ & - \\
\hline NO3 ( $\mu \mathrm{g} \mathrm{N} / \mathrm{l})$ & $1354 \pm 353$ & $708 \pm 73.1$ & $799 \pm 225$ & $628 \pm 238$ & $1325 \pm 332$ & - \\
\hline NH3 ( $\mu \mathrm{g} \mathrm{N} / 1)$ & $96 \pm 66.7$ & $40 \pm 40.5$ & $37 \pm 27.7$ & $14 \pm 11.1$ & $42 \pm 27.6$ & - \\
\hline \multicolumn{7}{|c|}{ Varaita } \\
\hline & March & April & May & June & July & August \\
\hline $\begin{array}{l}\text { COND } \\
(\mu \mathrm{S} / \mathrm{cm})\end{array}$ & $249 \pm 7$ & $226 \pm 0$ & $216 \pm 1$ & $228 \pm 11$ & - & - \\
\hline DO $(\%)$ & $103.1 \pm 2.76$ & $98.6 \pm 17.61$ & $103.7 \pm 8.41$ & $90.6 \pm 3.68$ & - & - \\
\hline DO (mgl/l) & $11.4 \pm 1.13$ & $11.2 \pm 1.41$ & $10.6 \pm 0.62$ & $8.2 \pm 0.66$ & - & - \\
\hline $\mathrm{pH}$ & $7.78 \pm 0.08$ & $8.02 \pm 0.09$ & $7.74 \pm 0.08$ & $8.00 \pm 0.06$ & - & - \\
\hline temp $\left({ }^{\circ} \mathrm{C}\right)$ & $12.3 \pm 1.20$ & $7.5 \pm 1.51$ & $14.1 \pm 1.53$ & $21.1 \pm 2.43$ & - & - \\
\hline $\mathrm{SRP}(\mu \mathrm{g} \mathrm{P} / 1)$ & $1.0 \pm 1.4$ & $5.0 \pm 1.52$ & $7.5 \pm 2.1$ & $0.5 \pm 0.7$ & - & - \\
\hline NO3 ( $\mu \mathrm{g}$ N/1) & $982 \pm 15$ & $733 \pm 39.1$ & $639 \pm 129$ & $501 \pm 6$ & - & - \\
\hline NH3 ( $\mu \mathrm{g} \mathrm{N} / 1)$ & $117 \pm 60$ & $38.4 \pm 7.67$ & $14.0 \pm 0.6$ & $55.0 \pm 9$ & - & - \\
\hline
\end{tabular}

Table 2. Results of the test of homogeneity for multivariate dispersion. Months = sampling month; UP vs DW sites = upstream vs. downstream sections; $\mathrm{MH}$ vs $\mathrm{T}=$ microhabitats vs. transect; Flow velocity $=$ lentic $(\mathrm{V}=0)$ vs. lotic $(\mathrm{V}>0)$ sections.

\begin{tabular}{|c|c|c|c|c|c|}
\hline \multicolumn{6}{|c|}{ Months } \\
\hline & Df & Sum Sq & Mean Sq & F value & $\operatorname{Pr}(>\mathbf{F})$ \\
\hline Groups & 5 & 0,05384 & 0,010767 & 0,5053 & 0,7715 \\
\hline Residuals & 83 & 1,76872 & 0,02131 & & \\
\hline \multicolumn{6}{|c|}{ UP vs DW sites } \\
\hline & Df & Sum Sq & Mean Sq & F value $P$ & $\operatorname{Pr}(>\mathbf{F})$ \\
\hline Groups & 1 & 0,07052 & 0,070521 & 3,7171 & 0,05712 \\
\hline Residuals & 87 & 1,65055 & 0,018972 & & \\
\hline \multicolumn{6}{|c|}{ MH vs T } \\
\hline & Df & Sum Sq & Mean Sq & F value & $\operatorname{Pr}(>\mathbf{F})$ \\
\hline Groups & 1 & 0,19251 & 0,192514 & 11,817 & $0.0009 * *$ \\
\hline Residuals & 87 & 1,41739 & 0,016292 & & \\
\hline
\end{tabular}

Post-hoc test

\begin{tabular}{cccccc} 
& \multicolumn{1}{c}{ diff } & & lwr & upr & p adj \\
& $-0,1002$ & & $-0,1581$ & $-0,0422$ & $\mathbf{0 , 0 0 0 9}$ \\
\hline \hline \multirow{3}{*}{ Groups } & Df & Sum Sq & Mean Sq & F value & Pr(>F) \\
& 1 & 0,13348 & 0,13348 & 7,767 & $\mathbf{0 . 0 0 6 5 * *}$
\end{tabular}


Residuals

Post-hoc test

\begin{tabular}{cccc} 
diff & lwr & upr & p adj \\
$-0,0775$ & $-0,1328$ & $-0,022$ & $\mathbf{0 , 0 0 6 5}$ \\
\hline
\end{tabular}

Table 3. Results of the PERMANOVA test. UP vs. DW = upstream vs downstream sections; Month = sampling month; River $=$ Po, Pellice or Varaita; $\mathrm{MH}$ vs. $\mathrm{T}=$ microhabitats vs transects.

\begin{tabular}{lcccccc}
\hline & Df & Sums of sqr & $\begin{array}{c}\text { Mean } \\
\text { Square }\end{array}$ & F. model & R2 & Pr (>F) \\
\hline \hline Month & 5 & 3,3940 & 0,6788 & 4,8387 & 0,2162 & $\mathbf{0 . 0 0 0 1} *$ \\
UP vs DW & 1 & 0,2805 & 0,2805 & 1,9994 & 0,0179 & $\mathbf{0 . 0 4 4 9 *}^{*}$ \\
MH vs T & 1 & 0,5701 & 0,5701 & 4,0640 & 0,0363 & $\mathbf{0 . 0 0 2 1}$ \\
Flow velocity & 1 & 0,2309 & 0,2309 & 1,6458 & 0,0147 & $\mathbf{0 , 1 7 0 0}$ \\
Residuals & 80 & 11,2229 & 0,1403 & & 0,7149 & \\
Total & 88 & 15,6984 & & & 1 & \\
\hline
\end{tabular}

Table 4. Results of the multi-way ANOVA to test significant differences in terms of ecological guilds, growth forms and eco-morphological groups with drought progression (month), in permanent or intermittent sections (UP vs DW), in the microhabitat or transects (MH vs $\mathrm{T}$ ) and under different flow velocities.

\begin{tabular}{|c|c|c|c|c|c|c|c|c|c|}
\hline & & \multicolumn{2}{|c|}{ Month } & \multicolumn{2}{|c|}{ UP vs DW } & \multicolumn{2}{|c|}{ MH vs T } & \multicolumn{2}{|c|}{ Velocity } \\
\hline & & $\mathrm{F}_{5,78}$ & $\mathrm{P}$ & $\mathrm{F}_{1,78}$ & $\mathrm{P}$ & $\mathrm{F}_{1,78}$ & $\mathrm{P}$ & $\mathrm{F}_{1,78}$ & $\mathrm{P}$ \\
\hline \multirow{4}{*}{$\begin{array}{l}\text { ECOLOGICAL } \\
\text { GUILDS }\end{array}$} & Motile & 4,720 & $<0.001$ & 0,208 & 0,649 & 0,557 & 0,458 & 0,004 & 0,952 \\
\hline & High & 8,957 & $<0.001$ & 0,117 & 0,734 & 5,969 & 0,017 & 0,027 & 0,871 \\
\hline & Low & 5,526 & $<0.001$ & 0,258 & 0,613 & 5,096 & 0,027 & 0,009 & 0,925 \\
\hline & Planctonik & 1,231 & 0,303 & 4,407 & $\mathbf{0 , 0 3 9}$ & 0,112 & 0,739 & 0,001 & 0,974 \\
\hline \multirow{5}{*}{ GROWTH FORMS } & Adnate & 3,717 & 0,005 & 1,019 & 0,316 & 0,741 & 0,392 & 0,864 & 0,356 \\
\hline & Mucous & 7,917 & $<0.001$ & 0,031 & 0,860 & 5,340 & 0,024 & 0,006 & 0,939 \\
\hline & Stalk & 2,981 & 0,016 & 0,912 & 0,343 & 2,671 & 0,106 & 0,563 & 0,456 \\
\hline & Pad & 2,582 & 0,032 & 1,022 & 0,315 & 0,078 & 0,781 & 1,103 & 0,297 \\
\hline & Colonial & 8,649 & $<0.001$ & 0,129 & 0,720 & 4,194 & 0,044 & 0,245 & 0,622 \\
\hline \multirow{2}{*}{ SIZE } & Size class & 0,550 & 0,738 & 0,440 & 0,509 & 0,003 & 0,957 & 1,957 & 0,166 \\
\hline & Biovolume & 1,080 & 0,379 & 1,270 & 0,263 & 0,750 & 0,389 & 1,920 & 0,170 \\
\hline \multirow{8}{*}{$\begin{array}{c}\text { ECO- } \\
\text { MORPHOLOGICAL } \\
\text { GROUPS }\end{array}$} & LS1 & 2,452 & 0,041 & 2,085 & 0,153 & 2,871 & 0,094 & 1,465 & 0,230 \\
\hline & LS2 & 6,110 & $<0.001$ & 5,368 & 0,023 & 10,946 & 0,001 & 0,009 & 0,926 \\
\hline & LS3 & 2,676 & 0,028 & 8,507 & 0,005 & 0,276 & 0,601 & 5,316 & 0,024 \\
\hline & LS4 & 3,143 & 0,012 & 3,637 & 0,060 & 1,480 & 0,227 & 1,375 & 0,245 \\
\hline & LS5 & 3,869 & 0,003 & 0,378 & 0,540 & 1,221 & 0,273 & 1,033 & 0,313 \\
\hline & HS1 & 2,380 & 0,046 & 1,771 & 0,187 & 0,016 & 0,900 & 1,460 & 0,231 \\
\hline & HS2 & 7,598 & $<0.001$ & 1,785 & 0,185 & 7,137 & 0,009 & 1,357 & 0,248 \\
\hline & HS3 & 4,016 & $\mathbf{0 , 0 0 3}$ & 0,728 & 0,396 & 3,080 & 0,083 & 0,021 & 0,886 \\
\hline
\end{tabular}




\begin{tabular}{|l|c|cc|cc|cc|cc} 
& HS4 & 5,401 & $<\mathbf{0 . 0 0 1}$ & 0,296 & 0,588 & 5,764 & $\mathbf{0 , 0 1 9}$ & 0,216 & 0,643 \\
& HS5 & 1,552 & 0,184 & 0,442 & 0,508 & 0,031 & 0,860 & 1,158 & 0,285 \\
& MS1 & 0,815 & 0,543 & 4,490 & $\mathbf{0 , 0 3 7}$ & 0,007 & 0,934 & 0,017 & 0,898 \\
& MS2 & 9,362 & $<\mathbf{0 . 0 0 1}$ & 0,025 & 0,876 & 0,057 & 0,811 & 2,475 & 0,120 \\
& MS3 & 1,441 & 0,219 & 0,340 & 0,561 & 1,676 & 0,199 & 1,170 & 0,283 \\
& MS4 & 4,122 & $\mathbf{0 , 0 0 2}$ & 0,425 & 0,516 & 0,810 & 0,371 & 4,455 & $\mathbf{0 , 0 3 8}$ \\
& MS5 & 6,091 & $\mathbf{0 . 0 0 1}$ & 2,860 & 0,095 & 0,060 & 0,807 & 0,134 & 0,715 \\
& PS1 & 1,055 & 0,392 & 3,099 & 0,082 & 0,007 & 0,933 & 2,236 & 0,139 \\
& PS3 & 2,071 & 0,078 & 0,836 & 0,363 & 0,040 & 0,842 & 1,206 & 0,276 \\
& PS4 & 1,507 & 0,197 & 1,016 & 0,317 & 0,019 & 0,889 & 0,058 & 0,811 \\
\hline
\end{tabular}

Electronic Supplementary Material 1. Complete checklist of diatom taxa detected in the three rivers during the experiment. The first two columns display the name and the OMNIDIA CODE of the taxa. The subsequent columns represent, respectively, the species growth form, the ecological guild to which the species belongs to, its mean biovolume and the eco-morphotype to which the species belongs. The last column shows the results of the Indicator Species Analysis on the following groups: SAMPLING MONTH (March, April, May, June, July, August); HABITAT (microhabitat -MH- or transect -T-); SITE LOCATION (upstream -UP- or downstream -DW- sections); FLOW VELOCITY (V=0 or V $>0 \mathrm{~m} / \mathrm{s})$.

Electronic Supplementary Material 2. Biological attributes of the diatom communities sampled in the three rivers, throughout the survey. Number of genera and species identified, Shannon diversity index and evenness (out of 400 individuals per sample). Percentage of relative abundance of eco-morphological guilds and growth forms detected in the three rivers throughout the survey. Mean values \pm standard deviations are calculated on T and MH samples of both UPDW sections. 